\title{
DESIGN OF A FPGA BASED ABWR FEEDWATER CONTROLLER
}

\author{
HSUANHAN HUANG, HWAIPWU CHOU*, and CHAUNG LIN \\ Department of Institute of Nuclear Engineering and Science, National Tsing Hua University \\ No. 101, Section 2, Kuang-Fu Road, Hsinchu, Taiwan 30013, R.O.C. \\ *Corresponding author. E-mail : hpc@ess.nthu.edu.tw \\ Invited September14, 2011 \\ Received October 27, 2011 \\ Accepted for Publication February 22, 2012
}

\begin{abstract}
A feedwater controller targeted for an ABWR has been implemented using a modern field programmable gate array (FPGA), and verified using the full scope simulator at Taipower's Lungmen nuclear power station. The adopted control algorithm is a rule-based fuzzy logic. Point to point validation of the FPGA circuit board has been executed using a digital pattern generator. The simulation model of the simulator was employed for verification and validation of the controller design under various plant initial conditions. The transient response and the steady state tracking ability were evaluated and showed satisfactory results. The present work has demonstrated that the FPGA based approach incorporated with a rule-based fuzzy logic control algorithm is a flexible yet feasible approach for feedwater controller design in nuclear power plant applications.
\end{abstract}

KEYWORDS : ABWR, Feed Water Controller, Fuzzy Control, FPGA

\section{INTRODUCTION}

The water level in an advanced boiling water reactor (ABWR) is subject to shrink-and-swell phenomena. For this reason, a control action might be incorrect at the beginning of a transient that has a large steam flow rate or pressure change. A poor control system design may result in too little or too much water inventory in the reactor vessel, which may lead to a low- or high-level trip. It is thus important to have a properly designed feedwater control system to improve plant availability.

The water level in an ABWR is affected by many factors, such as changes in the steam flow rate, feedwater flow rate, vessel pressure, and reactor power. Traditionally, the water level is controlled by a three-element controller that is composed of steam- feedwater flow rate feedforward and water level feedback control, which are both PIcontrollers. The controller output is used to adjust the feedwater flow rate by turbine driven reactor feedwater pumps (TDRFP) in the normal power model. The performance of the PI controller is quite good during transients, but the settling time is rather long. Many modern control techniques have been proposed, including the fuzzy logic controller (FLC), which is based on a skilled operator's experience. The major advantages of the FLC are that it can work well in a non-linear manner and is useful for a wide operational range. Therefore, the FLC is a promising candidate for ABWR water level control ${ }^{[1]}{ }^{[2]}$.
Taipower's Lungmen nuclear power station is an ABWR. Its instrumentation and control system is a fully digital system. In the present study, the FLC is implemented using a modern field programmable gate array (FPGA), which is a digital integrated circuit and is programmable for any type of digital function. Compared to microprocessor chips, a programmed FPGA is hardware, and as such does not introduce any software verification and validation problems. In addition, it has the advantages of low cost and flexibility for implementation ${ }^{[3]}$.

In the following sections, the FLC design is presented first. The verification and validation process of the controller design, using a full scope simulator, is described. Implementation and testing results are then shown.

\section{HIERARCHICAL FUZZY LOGIC CONTROLLER}

In the present study, a hierarchical fuzzy logic controller is adopted. The antecedent part of the control rule of the FLC contains error, change in error, and other physical measurements often utilized to enhance the controller's performance. However, when the number of system variables is increased, the number of control rule matrices, and thus the number of final decision tables, is increased very rapidly. To solve this problem, a hierarchical rule structure, as shown in Fig.1, is adopted; the structure is similar to that used in Ref. [2]. It has been shown that the 
total number of rules will reach the minimum value when the number of linguistic variables contained in each level is two. The hierarchical structure is established as follows: the two most influential system variables are arranged in the first level according to their degree of importance. The output of the first level and the next most important variable are arranged in the second level, and so on.

In this study, three system variables were considered: the water-level error $\mathrm{E}$, the change in waterlevel error $\mathrm{CE}$, and the difference between the feedwater and steam flow rate DFS, where

$\mathrm{E}=$ measured water-level - water-level setpoint

$\mathrm{CE}=(\mathrm{E}$ at time $\mathrm{k} \mathrm{T})-[\mathrm{E}$ at time $(\mathrm{k}-1) \mathrm{T}]$

$\mathrm{DFS}=$ feedwater flow rate - steam flow rate

$\mathrm{T}=$ the sampling period.

As shown in Fig.1, the first level inputs are $\mathrm{E}_{\text {(input 1.1) }}$ and $\mathrm{CE}_{\text {(input 1.2) }}$ and the second level input is DFS (input 2). The consequent part of the control rule is the change in the feedwater pump signal $\mathrm{CF}$ (output 2). The control matrix of $\mathrm{E}$ and CE is shown in Table 1, and that of DFS is show in Table 2.

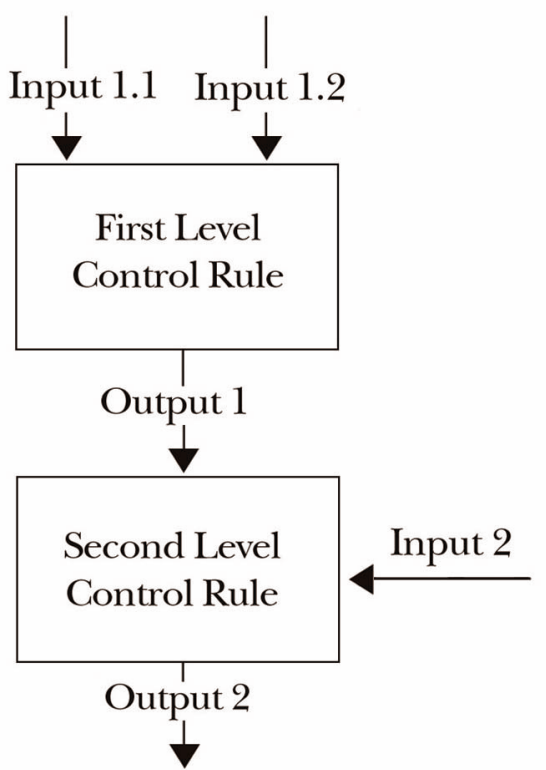

Fig. 1. Hierarchical Structure.

Table 1. The First Level of the Hierarchical Rule Matrix

\begin{tabular}{|c|c|c|c|c|c|c|c|c|c|}
\hline \multirow{2}{*}{$\begin{array}{c}\mathrm{CE} \\
\text { (input 1.2) }\end{array}$} & \multicolumn{9}{|c|}{$\mathrm{E}$ (input 1.1) } \\
\hline & NB & $\mathrm{NM}$ & NS & $\mathrm{NZ}$ & $\mathrm{ZO}$ & $\mathrm{PZ}$ & PS & $\mathrm{PM}$ & PB \\
\hline NB & PB & PB & PB & $\mathrm{PM}$ & $\mathrm{PM}$ & PS & PS & $\mathrm{PZ}$ & $\mathrm{NZ}$ \\
\hline $\mathrm{NM}$ & PB & PB & PM & $\mathrm{PM}$ & PS & PS & $\mathrm{PZ}$ & $\mathrm{NZ}$ & NS \\
\hline NS & PB & $\mathrm{PM}$ & PM & PM & PS & $\mathrm{PZ}$ & $\mathrm{NZ}$ & $\mathrm{NZ}$ & $\mathrm{NM}$ \\
\hline $\mathrm{NZ}$ & $\mathrm{PB}$ & $\mathrm{PM}$ & $\mathrm{PM}$ & PS & $\mathrm{PZ}$ & $\mathrm{ZO}$ & $\mathrm{NZ}$ & NS & NM \\
\hline $\mathrm{ZO}$ & $\mathrm{PB}$ & PM & PS & $\mathrm{PZ}$ & $\mathrm{ZO}$ & $\mathrm{NZ}$ & $\mathrm{NS}$ & $\mathrm{NM}$ & NB \\
\hline $\mathrm{PZ}$ & $\mathrm{PM}$ & PS & $\mathrm{PZ}$ & $\mathrm{ZO}$ & $\mathrm{NZ}$ & NS & NM & NM & NB \\
\hline PS & $\mathrm{PM}$ & $\mathrm{PZ}$ & $\mathrm{PZ}$ & $\mathrm{NZ}$ & NS & NM & NM & NM & NB \\
\hline PM & PS & $\mathrm{PZ}$ & $\mathrm{NZ}$ & NS & NS & NM & NM & $\mathrm{NB}$ & NB \\
\hline PB & $\mathrm{PZ}$ & $\mathrm{NZ}$ & NS & NS & $\mathrm{NM}$ & $\mathrm{NM}$ & NB & NB & NB \\
\hline
\end{tabular}

Table 2. The Second Level of the Hierarchical Rule Matrix

\begin{tabular}{|c|c|c|c|c|c|c|c|c|c|}
\hline \multirow{2}{*}{$\begin{array}{c}\text { DFS } \\
\text { (input 2) }\end{array}$} & \multicolumn{9}{|c|}{ First level output (output 1) } \\
\hline & NB & NM & NS & $\mathrm{NZ}$ & $\mathrm{ZO}$ & $\mathrm{PZ}$ & PS & PM & $\mathrm{PB}$ \\
\hline NB & NB & $\mathrm{NZ}$ & $\mathrm{ZO}$ & $\mathrm{PZ}$ & PS & PM & PB & PB & PB \\
\hline NM & NB & NS & $\mathrm{NZ}$ & $\mathrm{ZO}$ & $\mathrm{ZO}$ & PS & PM & $\mathrm{PB}$ & PB \\
\hline $\mathrm{ZO}$ & NB & NM & NS & $\mathrm{NZ}$ & $\mathrm{ZO}$ & $\mathrm{PZ}$ & PS & PM & PB \\
\hline PM & NB & $\mathrm{NB}$ & NM & NS & $\mathrm{ZO}$ & $\mathrm{ZO}$ & $\mathrm{PZ}$ & PS & $\mathrm{PB}$ \\
\hline PB & NB & NB & NB & NM & NS & $\mathrm{NZ}$ & $\mathrm{ZO}$ & $\mathrm{PZ}$ & PB \\
\hline
\end{tabular}


The membership functions are shown in Fig. 2. The membership function of the second level $\mathrm{CF}_{\text {(output 2) }}$ is nonlinear because it will lead to a faster response. A max-product inference method and a center-of-gravity defuzzification procedure were used to obtain two lookup tables, which are also called decision tables.

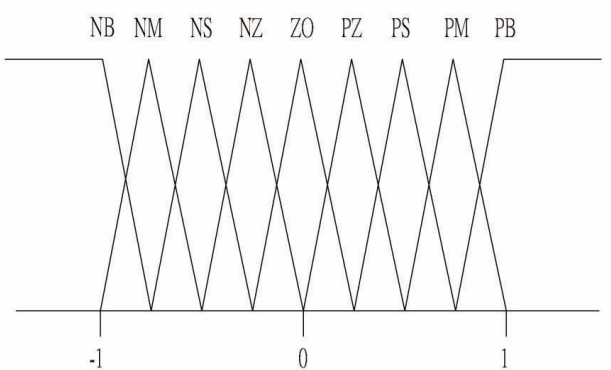

(a)

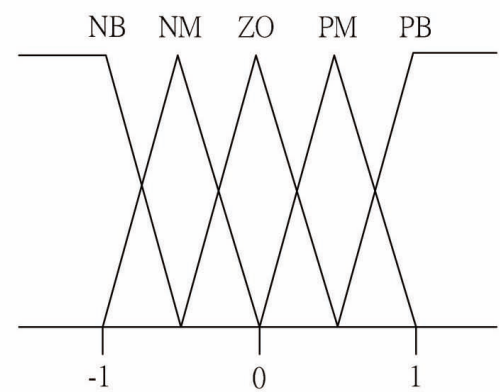

(b)

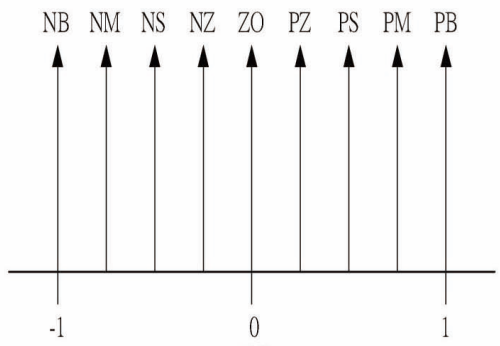

(c)



(d)

Fig. 2. Membership Functions (a) of E and CE, (b) of DFS, (c) of the First-level CF, and (d) of the Second-level CF
The physical signal must be scaled by a scaling factor and quantized during the control procedure. The signal can then be used for the decision tables. The scaling factors are named GE, GCE, GF, and GU for E, EC, DFS, and $\mathrm{CF}$, respectively. GE is a constant scaling factor, and the others are nonlinear factors. In Fig. 3a, a nonlinear factor NF was multiplied to GCE to speed up the response when $\mathrm{E}$ is large and to reduce fluctuations when $\mathrm{E}$ is small. Another NF, shown in Fig. 3b, was multiplied to GF to get closer to the setpoint when $\mathrm{E}$ is small. And, in Fig. 3c, NF was multiplied to GU to obtain a smaller output when $\mathrm{E}$ is small.

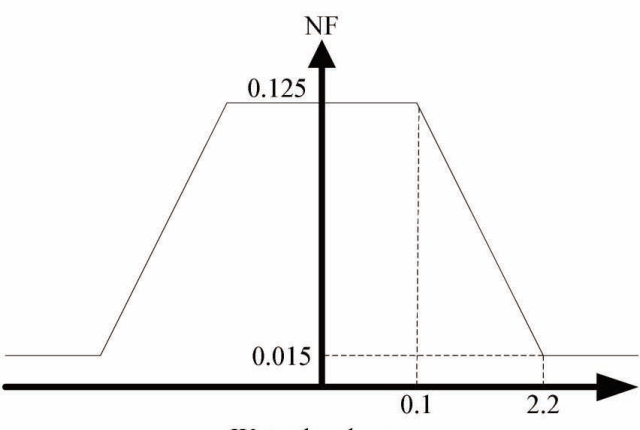

Water level error

(cm)

(a)

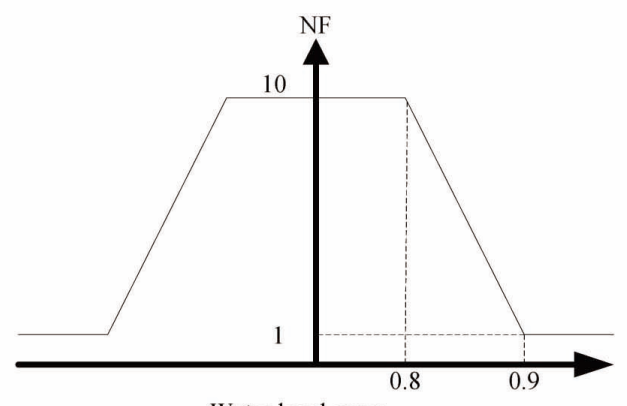

Water level error

$(\mathrm{cm})$

(b)

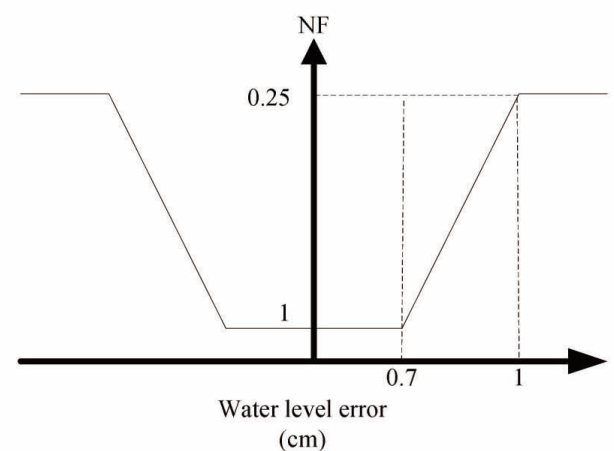

(cm)

(c)

Fig. 3. Nonlinear Factor for (a) GCE, (b) GF and (c) GU 


\section{SIMULATION SOFTWARE}

3KEYMASTER ${ }^{\text {TM }}$ is a state-of-the-art software tool and features a rich MS Windows®-based system for the development of simulation software. The MASTER Instructor Station \& Graphical Engineering Station is one of the many MASTER series of graphical products developed by WSC for simulation and engineering purposes. The MASTER Graphical Engineering Station can be used to model, develop, and run simulation software. In this study, the simulation model of Lungmen nuclear power station is run in the MASTER Graphical Engineering Station for verification and validation of the fuzzy controller.

A three-element controller and the fuzzy controller were compared. For each system, tests were run at the full power state and four transitions: the water level set point changed from $425 \mathrm{~cm}$ to $440 \mathrm{~cm}$, the water level set point changed from $440 \mathrm{~cm}$ to $425 \mathrm{~cm}$, and the reactor core power level reduced by $10 \%$ and by $20 \%$. At the full power state, the water level is controlled by adjusting the rotation rate of two turbine driven reactor feedwater pumps (TDRFP). The TDRFP is driven by steam that enters the pump, controlled by a motor control valve (MCV), from the main steam tunnel. Thus, by controlling the opening degree of the valve, the rotation rate of the TDRFP and the feedwater flow rate can be adjusted.

As seen in Fig. 4, the three-element controller sends a signal to change the rotation rate to the main feedwater turbine electron-hydraulic controller (MFTE). The MFTE then transforms the signal into the relative degree of valve opening demand, and controls the MCV to adjust the TDRFP rotation speed. To replace the three-element controller, the output of the FLC was connected to the MFTE when it was tested.

\section{HARDWARE IMPLEMENTATION}

A typical digital controller is based on a microprocessor and software technology. However, unlike a microcontroller, the FPGA chip functions as a piece of hardware after being configured. In this study, we did not use any microprocessor and only used a logic gate in the FPGA chip.

A FPGA chip is used to implement the FLC, as described in Section 2, and is connected to the 3Keymaster simulator for testing. The FPGA device in this study is Spartan-3E XC3S1600E. The electrical design automation (EDA) software tools used are Xilinx ISE 11.1. The interface between the FPGA and a personal computer (PC) is through the asynchronous protocol, RS232, which allows bidirectional full-duplex communication; this means the $\mathrm{PC}$ can send and receive data at the same time. The communication speed is set at 115200 bauds. Because the sampling rate of 3 keymaster was 8 cycles per second in the study, the communication speed is fast enough for data transfer. Using the EDA simulation tool, the size of the designed FLC is small. Since the communication speed is relatively slow, other types of FPGA chips can also be used to replace XC3S1600E easily.

Two lookup tables were established in the FPGA. The two tables were calculated and used for off-line hierarchical FLC. The data received from the PC were classified as E, EC, or DFS, and then were transmitted to the two lookup tables. The two tables are hierarchical rule matrices. As described in Section 1 and as shown in Fig. 1, the inputs of the first level table are E and EC, and the second level inputs are the first level output and DFS. The second level output is sequentially sent back to the $\mathrm{PC}$ as the pump speed demand signal. A block diagram of the FLC in the FPGA is shown in Fig. 5.

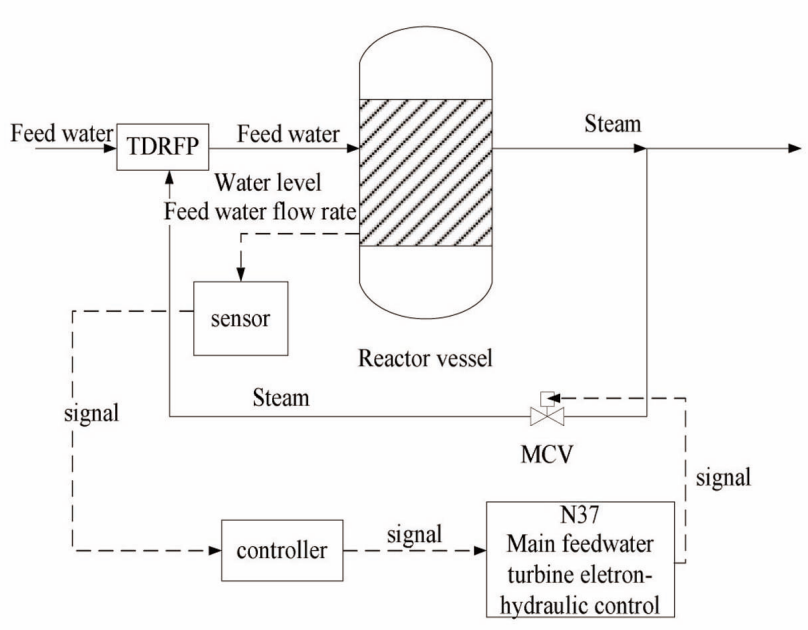

Fig. 4. Schematic of the Feedwater Controller

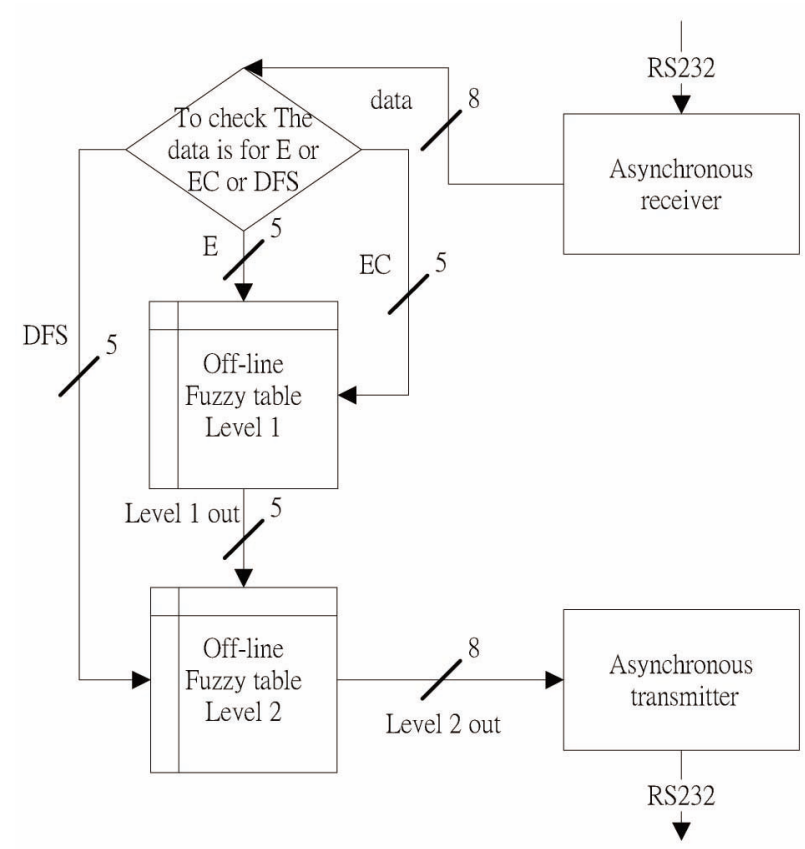

Fig. 5. Block Diagram of FLC in FPGA 
The FPGA is programmed using the embedded supporting software. A C program is used to validate the values of the tables in the FPGA. The program will transfer every value of E, CE, and DFS and then record the signal, which is returned from the FPGA. Every value of the fuzzy table in the FPGA is checked.

It is known that the FPGA and the microcontroller should follow the same development guidance. However, this paper is an academic study, and our goal is to make a preliminary assessment. Hence, this paper mainly concentrates on simulator based on-line virtual closedloop testing for integrated control function.

\section{PERFORMANCE COMPARISONS}

The values of the designed FLC scaling factors are $\mathrm{GE}=0.67, \mathrm{GCE}=10, \mathrm{GF}=0.00335$, and $\mathrm{GU}=0.1667$. GE and GCE are multiplied by NF in Fig. 3. These numbers were decided by trial and error.

Figures 7, 8, 9, and 10 show a comparison of a three element (3E) control system, which is composed of two PI controllers, and the FLC established in FPGA. Figure 7 shows the results for a set point changed from 425 to $440 \mathrm{~cm}$; Fig. 8 shows the results for the set point changed from 440 to $425 \mathrm{~cm}$. The rise time of the $3 \mathrm{E}$ controller is shorter in Figs. 7a and 8a, but the setting time is longer and the over-shoot is larger. In Figs. $7 \mathrm{~b}$ and $8 \mathrm{~b}$, the PI controller produces a larger feedwater flow rate at the

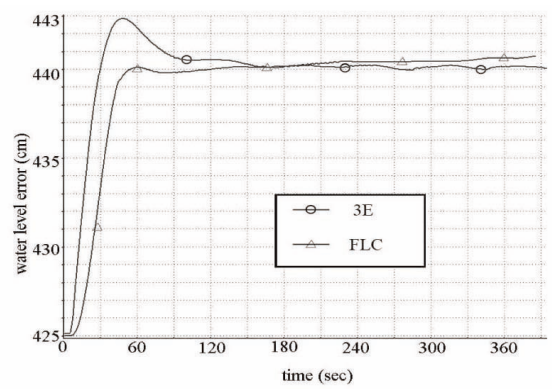

(a)

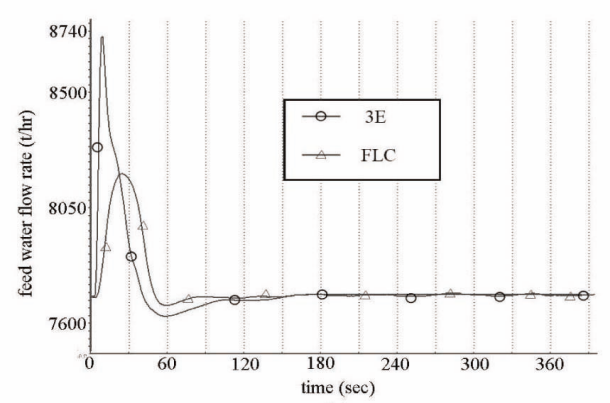

(b)

Fig. 7. Performance Comparisons for $15-\mathrm{cm}$ Set Point upChange for (a) Water Level and (b) Feed Water Flow Rate

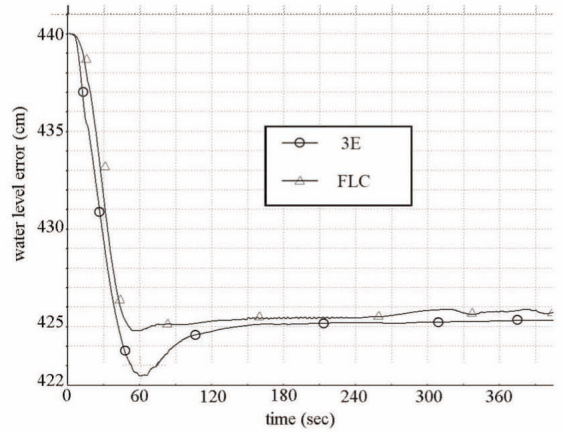

(a)



(b)

Fig. 8. Performance Comparisons for 15-cm Setpoint DownChange for (a) Water Level and (b) Feed Water Flow Rate

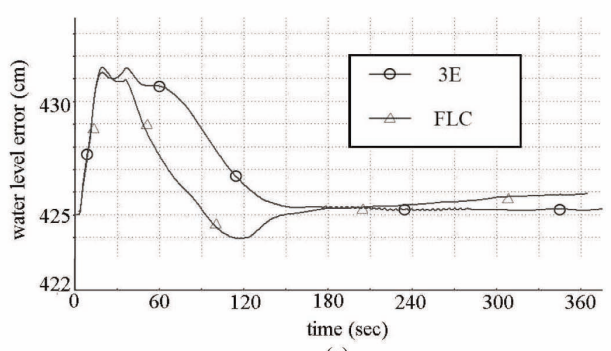

(a)

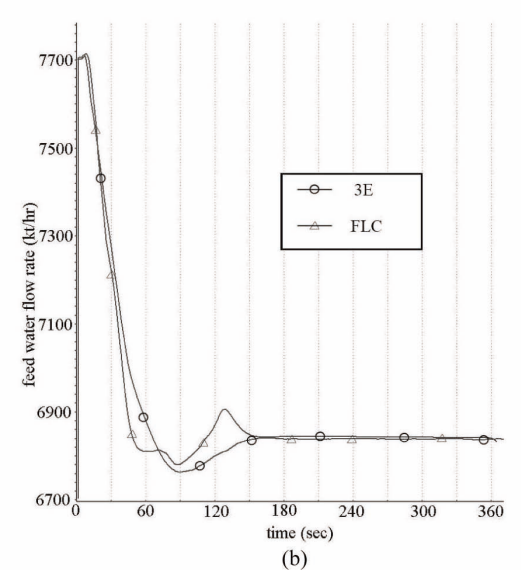

Fig. 9. Performance Comparisons for Load Demand Change from 100 to $90 \%$ for (a) Water Level and (b) Feed Water Flow Rate 


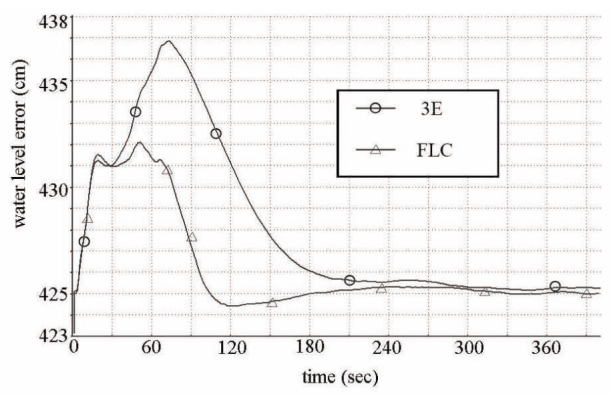

(a)

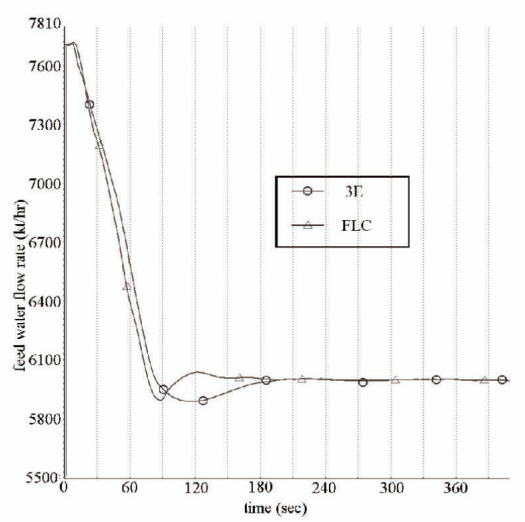

(b)

Fig. 10. Performance Comparisons for Load Demand Change from 100 to $80 \%$ for (a) Water Level and (b) Feed Water Flow Rate

beginning than the FLC. The feedwater flow rate given by the FLC has a smaller change, which means the FLC used less control effort than the PI controller.

To compare the disturbance rejection performance, the thermal power was changed from 100 to $90 \%$, as seen in Fig. 9, and from 100 to $80 \%$, in Fig. 10, by changing the reactor internal pump (RIP) percent speed setting from 88 to $72 \%$ and $56 \%$. When the RIP speed decreases, the thermal power and the steam flow rate will decrease. In Fig. 9a, the overshoot and setting time are similar, but undershoot of the FLC is larger and the settling time is larger. In Fig. 9b, The PI controller caused a smoother change of the feedwater flow rate. Shortcomings seen in Fig. 9 can be improved by adjusting the FLC rule tables. For a larger thermal power change, i.e., 20\%, the FLC has a shorter settling time and overshoot, but still has undershoot, as shown in Fig. 10. The FLC is more suitable than the PI controller for large transients.

\section{CONCLUSIONS}

The present study proposes a hierarchical FLC targeted for ABWR feedwater level control. The controller has been implemented by using a FPGA and is connected to a 3KEYMASTER simulator for testing. The hierarchical rule structure reduces the number of decision tables and thus simplifies the controller design. The simulation model of the full scope simulator at Taipower's Lungmen nuclear power station was employed for verification and validation of the controller design under various plant initial conditions. The simulation results show that the FLC provides better performance than the PI controller. The FLC produced a shorter settling time and smaller overshoot than the PI controller, but the rise time was longer and the FLC had some undershoot, which can be improved by adjusting the FLC rule tables.

Although the preliminary simulation results are satisfactory compared with the traditional PI controllers, further work should be done. More initial conditions will be tested in future studies, such as variation of the reactor core temperature and pressure, which are important during the startup and shutdown of the reactor. Furthermore, the FLC will be integrated with other subsystems of the ABWR feedwater control system and implemented using an FPGA chip for practical control application.

\section{ACKNOWLEDGEMENT}

This research was funded by the National Science Council, Taiwan. Technical support by A-D Technology Company and Taipower Company are gratefully acknowledged.

\section{REFERENCES}

[1 ] T. Iijima, Y. Nakajima and Y. Nishiwaki,"Application of Fuzzy Logic Control System for Reactor Feed-Water Control,’ Fuzzy Sets and Systems, vol. 74, pp. 61-72(1995).

[2] F. L. Cheng and C. Lin, "Hierarchical Fuzzy Logic Control of Water Level in ABWR," Nucl. Technol., vol. 118, pp. 254-263 (1997).

[3] M. Mckenna and B. M. Wilamowski, "Implementing a Fuzzy System on a Field Programmable Gate Array," Proc. Int. Joint Conf. on Neural Networks, vol. 1, pp. 189-194 (2001).

[4] A. Fukumoto, T. Hayashia, H. Nishikawa, H. Sakamoto, T. Tomizawa and T. Yokomura, "A Verification and Validation Method and its Application to Digital Safety Systems in ABWR Nuclear Power Plants," Nuclear Engineering and Design, vol. 183, pp. 117-132(1998). 